\title{
Diffusion model simulation of odor pollutants in livestock and poultry farms based on environmental monitoring of the Internet of Things
}

\author{
Jing ZHANG ${ }^{1}$, Liwei Xing ${ }^{1}$, Guodong $\mathrm{CHENG}^{1}$, Yonghan $\mathrm{WANG}^{1}$, Shuqing HAN ${ }^{1 *}$ \\ ${ }^{1}$ Agricultural Information Institute, Chinese Academy of Agricultural Sciences/Key Laboratory of Agricultural Big Data, Ministry of \\ Agriculture and Rural Affairs, Beijing, 100081, China
}

\begin{abstract}
Livestock pollution is one of the main sources of agricultural pollution, which has a negative impact on the global environment. Monitoring, simulation and early warning of major pollutants emitted from livestock production is of great significance for reducing agricultural pollution. Especially, real-time comprehensive monitoring and early warning of the concentration and distribution of harmful gases could improve the harm of livestock production to people, livestock itself and the environment, and increase the safety level of livestock production. This study focused on the perception and monitoring of the discharge status of livestock farming simulation technics, mainly to carry out Internet of Things-based monitoring of the main components of livestock culture pollutants, and to use odor gas air dispersion software "ModOdor" to simulate the spread of pollutants. This study was aimed to determine the characteristics of pollutant diffusion in typical farms, which could provide decision reference to odor hygienic buffer zone and minimum shelter distance to achieve the ecological and safety objectives of livestock farming.
\end{abstract}

\section{Odor pollution characteristics of livestock and poultry farms}

\subsection{Sources of odor pollutants in livestock and poultry farms}

The stench of farms mainly comes from the corrupt decomposition of livestock and poultry droppings. Organic matter in feces mainly includes carbohydrates and nitrogen-containing compounds. These organisms break down under aerobic or anaerobic conditions. Carbohydrates release heat when aerobic decomposition occurs, the main products are $\mathrm{CO}_{2}$ and water, but under anaerobic conditions, its decomposition products are mainly methanol, organic acids and various alcohols, these substances are slightly odor and acidic, which would make people feel unpleasant. Nitrogen-containing compounds are decomposed into amino acids under the enzyme, and then decomposed into nitrates under aerobic conditions, and decomposed into ammonia, sulfuric acid, ethylene alcohol, dimethyl thioether, methylamine, trimethylamine and other odors, which have rotting onion odor, rotten egg odor, fish odor and other unique odors.

\subsection{The main components of odor pollution and the release source intensity}

The main odor pollutants produced by livestock and poultry farms include ammonia $\left(\mathrm{NH}_{3}\right)$ and hydrogen sulfide $\left(\mathrm{H}_{2} \mathrm{~S}\right)$. Nitrogen-containing organic matter in animal and poultry manure breaks down to produce ammonia under the effect of urea enzymes. The evaporation of ammonia can occur at all stages of livestock and poultry production, but mainly in the process of fecal urination and fecal storage, as well as after usage into soil. Microorganisms in livestock farms break down sulfur-containing organic matter from sulfates and feces in water into $\mathrm{H}_{2} \mathrm{~S}$ gases inanaerobic environments. The sources of $\mathrm{H}_{2} \mathrm{~S}$ mainly include feces that are not cleaned in the animal house in time, as well as manure stirring, biogas pumping out fertilization, marsh slag cleaning and so on.

The odorous composition of livestock and poultry is complex, which mainly include volatile fatty acids (VFAs), phenols, alcohols, aldehydes, ketones, esters, ethers, amines, hydrocarbons, halogenated hydrocarbons, sulphides, nitrogen heterocyclics, and aromatic ${ }^{[1-5]}$. Various types of VOCs contain different substances that can be further subclassed into subclasses. In addition to organic components, odorous substances include inorganic components such as ammonia and hydrogen sulfide ${ }^{[6]}$. Due to the complexity and diversity of animal and poultry odorous substances formed under different conditions, and the easy migration and transformation in the atmosphere, it is not entirely clear how to pay tribute to the stench of livestock and poultry under all kinds of odorous substances. From the existing studies, it is generally believed that the substances that play a key role in the odor of livestock and poultry are mainly volatile fatty acids, sulfur-containing compounds, aromatic

*Corresponding author: hanshuqing@caas.cn 
compounds (mainly phenols and benzpyrole), as well as ammonia and volatile amine ${ }^{[7-9]}$.

VFAs are considered to be the most important component of animal and poultry odors. About $60 \%$ of VFAs are acetic acid, followed by acetic acid, orthobutyric acid, isobutyric acid, isoprene acid, orthoic acid, and oxalic acid. Sulfur-containing compounds generally have a strong irritating odor and are an important component of the odorous substances of livestock and poultry. Of the substances with the lowest odor thresholds identified, 6 are sulphide-containing compounds. The main sulfur-containing compounds are hydrogen sulfide, methanol, propylene thiol, dimethyl ether, dimethyl dithion ether. Most of the sulfur in livestock droppings is distributed into the air in the form of hydrogen sulfide and methanol, and 2 substances account for $70 \%$ to $97 \%$ of volatile sulfur-containing odors in livestock and poultry. Pig droppings Volatile hydrogen sulfide mass concentration reached 90 $\mu \mathrm{g} \cdot \mathrm{m}^{-3[10]}$, while pig house air methanol mass concentration reached $3.6 \times 10^{4} \mu \mathrm{g} \cdot \mathrm{m}^{-3}$, which is 947 to $120 \times 10^{6}$ times the self-smell threshold ${ }^{[11]}$, because methanol is considered to contribute the most to the odor of livestock and poultry sulfur compounds. Under normal circumstances, the concentration of sulfur-containing compounds is significantly higher than VFAs, and the odor threshold of sulfur-containing compounds is lower than VFAs, so sulfur-containing compounds are generally considered to play a stronger role in odor than VFAs.

Ammonia has a strong irritating odor, and compared with other odorous components, ammonia has a relatively high odor threshold $\left(0.3 \times 10^{-6}-53 \times 10^{-6}\right)$, so in early studies ammonia was once considered as the only indicator of the odor of livestock and poultry ${ }^{[12-13]}$, so far many countries have also used ammonia as the main indicator of odor evaluation ${ }^{[14]}$. However, it has also been

Table 1. Cow manure $\mathrm{NH}_{3}$ release source intensity $\left(\mathrm{kgNH}_{3} /\right.$ head $\times$ years $)$ under different breeding conditions

\begin{tabular}{lllll}
\hline Farming methods & The type of cowhouse & Cowhouse & Storage & $\begin{array}{l}\text { Release } \\
\text { intensity }\end{array}$ \\
\hline \multirow{2}{*}{ Raised separately } & "solid floor type" & "straw mat type" & 11.50 & 5.78 \\
Intensive breeding & & 4.00 & 6.90 & 17.28 \\
Literature results & & 6.55 & 6.25 & 10.9 \\
\hline
\end{tabular}

\subsubsection{Release source intensity of odor pollution from pig farms}

household free-range method is of high intensity than the intensive breeding emission source. Under intensive breeding, $\mathrm{NH}_{3}$ is the most volatile in pigpens. The amount of $\mathrm{NH}_{3}$ distributed in the process of pig manure storage in China is large.

The $\mathrm{NH}_{3}$ Release source intensity of different pig breeds under different breeding methods in China is shown in Table 2. Among them, the $\mathrm{NH}_{3}$ emission source of the

Table 2. $\mathrm{NH}_{3}$ release source intensity $\left(\mathrm{kgNH}_{3} /\right.$ head $\times$ years $)$ in different breeding conditions in China

\begin{tabular}{|c|c|c|c|c|c|c|}
\hline \multicolumn{2}{|c|}{ Breeding methods } & Pig species & $\begin{array}{l}\text { Ways to store dung } \\
\text { and urine }\end{array}$ & Pigpen & Storage & $\begin{array}{l}\text { release source } \\
\text { intensity }\end{array}$ \\
\hline \multirow{4}{*}{\multicolumn{2}{|c|}{ household free-rang }} & \multirow{2}{*}{ Adult sow } & Composting mode $^{a}$ & 5.40 & 7.38 & 12.78 \\
\hline & & & Biogas mode & 5.40 & 2.46 & 7.86 \\
\hline & & \multirow{2}{*}{ Fattening pigs } & Composting mode & 2.97 & 4.06 & 7.03 \\
\hline & & & Biogas mode $b$ & 2.97 & 1.35 & 4.32 \\
\hline \multirow{3}{*}{$\begin{array}{l}\text { Intensive } \\
\text { breeding }\end{array}$} & \multirow{2}{*}{ Domestic } & Adult sow & & 4.23 & 0.67 & 4.90 \\
\hline & & Fattening pigs & & 2.45 & 0.30 & 2.75 \\
\hline & Foreign & Piglets & & 0.42 & 0.06 & 0.48 \\
\hline
\end{tabular}


Fattening pigs

Adult sow

At present, domestic and foreign research on the release of livestock and poultry $\mathrm{H}_{2} \mathrm{~S}$, especially long-term and high-frequency monitoring is less, the existing research mainly focused on the concentration of $\mathrm{H}_{2} \mathrm{~S}$ in pigpens.

\subsubsection{Release source intensity of odor pollution from laying hens farms}

In 2002, Lim et al. measured $\mathrm{H}_{2} \mathrm{~S}$ concentrations of $4.71 \mu \mathrm{g} / \mathrm{m}^{3}$ and $29.9 \mu \mathrm{g} / \mathrm{m}^{3}{ }^{[20]}$ in vents and exhaust vents of a nearly 250,000-scale laying hens farm. Studies shown that the volatile amount of $\mathrm{NH}_{3}$ in livestock and poultry feces is generally $0.007 \%-0.354 \%$ of the total amount of feces, while the volatile amount of $\mathrm{NH}_{3}$ in cow dung is $18.6 \%$ of pig manure, while the $\mathrm{NH}_{3}$ volatility of chicken manure is 1.8 times that of pig manure.

\section{Internet of Things-based monitoring of livestock and poultry farming environments}

\subsection{Monitoring equipment and platforms}

Based on IoT facilities, data on the concentration of major pollutants in livestock and poultry farms are collected and analysis. In recent years, relying on the Agricultural Internet of Things integrated service platform, Chinese Academy of Agricultural Sciences (CAAS), the team has developed 1 set of environmental monitoring equipment for livestock and poultry, which include the environmental senser and monitor, control device, information management platform and mobile phone APP program. As shown in the following Fig. 1.(a) (e). At present, the agricultural Internet of Things closed-loop system with a set of perceptual layer, network layer and application layer has been initially formed, which provides technical support for the monitoring of animal husbandry dung pollution, and can provide equipment support for the monitoring of the whole all-round environment of animal husbandry.

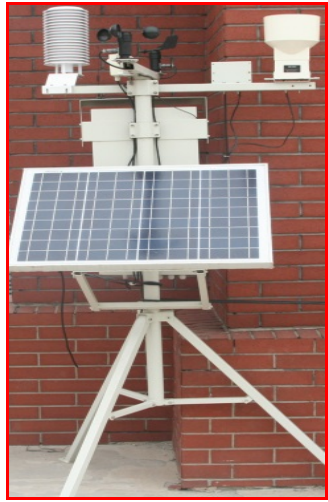

(a) Environmental monitors outside livestock sheds $\begin{array}{lll}2.89 & 0.85 & 3.74\end{array}$

7.43

2.18

9.61

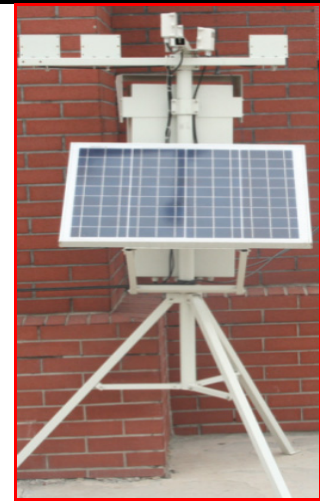

(b) Environmental monitors in livestock sheds

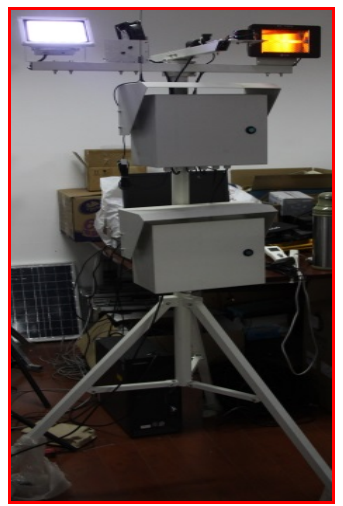

(c) animal husbandry control devices

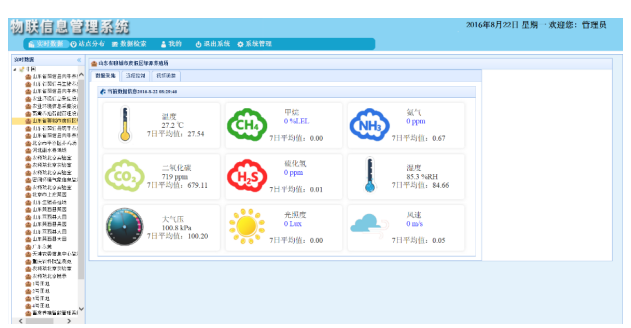

(d) Livestock environmental monitoring information management platform

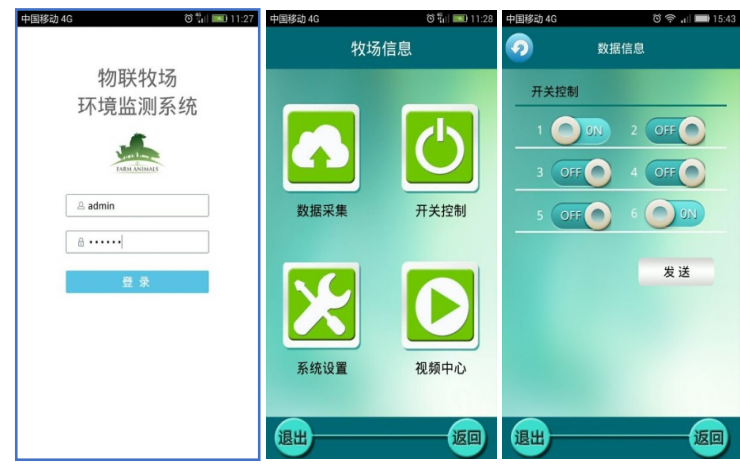

(e) Livestock environment monitoring mobile app program

Fig. 1. Hardware and systems for animal environmental monitoring 


\subsection{Environmental monitoring indicators for livestock farming}

Based on field research in 4 provinces and cities and 11 farms, 15 key monitoring indicators and threshold ranges suitable for animal growth were finally determined through the analysis and screening of 15 meteorological indicators and 10 gas indicators, providing adjustment parameters for the realization of environmental automation control. Meteorological monitoring indicators (10): temperature, humidity, atmospheric pressure, light intensity, wind, windspeed, rainfall, PM2.5, PM10, radiation intensity; gas monitoring indicators (5): $\mathrm{NH}_{3}, \mathrm{H}_{2} \mathrm{~S}, \mathrm{CO}_{2}, \mathrm{CH}_{4}, \mathrm{O}_{2}$.

\section{ModOdor-Odor Gas Air Dispersion Software}

\subsection{Introduction to the ModOdor model}

Odor gas air dispersion software (Modeling of Odor gas air dispersion software, ModOdor v1.0, 2014) is from a special key project of Environmental Protection Public Welfare Industry Research of the Ministry of Environmental Protection "Solid waste disposal Facilities Environmental Safety Evaluation Technology Research" (2012.1-2014.12) supported by Tsinghua University, which is developed by Tsinghua University for solid waste disposal facilities and other pollution sources generated by the atmospheric diffusion simulation and concentration forecast. ModOdor, although developed for atmospheric diffusion of foul-smelling gases, is also suitable for the simulation of atmospheric diffusion of other gaseous pollutants on a small and medium scale.

Based on convection diffusion equation, ModOdor can be applied to the numerical solution model software for the atmospheric diffusion of local-scale odorous gases and can be used for atmospheric diffusion simulation \& concentration prediction of odorous gases. ModOdor realized the numerical simulation method of the finite difference between the three-dimensional atmospheric diffusion of pollutants, focusing on the atmospheric diffusion of pollutants in medium and small-scale research areas.

ModOdor enables multiple pollutant composition simulations that can simultaneously simulate atmospheric diffusion of up to 60 compositions. At the same time, ModOdor is able to simulate up to 3000 wind speed field scenarios simultaneously when the wind speed field is selected for the same wind speed across the region.

To make the software easier for users to use, ModOdor uses a consistent window form to build the solution, as shown in Fig. 2. The user interface of the solution consists of 2 sub-windows: the upper sub-window is a conditional window, mainly used for parameter entry, conditional selection, running operations, etc., and the sub-window is composed of a simple text editor in RTF format, which is mainly used to display the results of the calculation. When ModOdor completes the calculation, the new calculation is placed in this window. ModOdor provides default data support system, full data entry interface system, entry error automatic identification system, entry parameter legitimacy check system, function and formula entry system, calculation results illustration system, help system, users can easily, easily and quickly enter parameters, implement calculations and draw calculation results of the drawing (Fig. 3.).

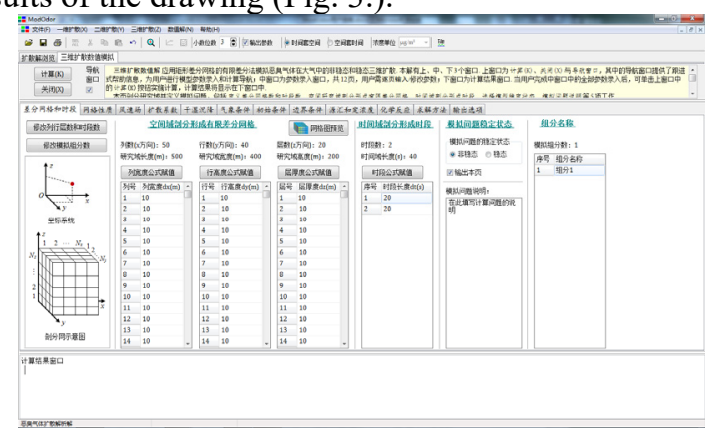

Fig. 2. ModOdor 3D diffusion numerical solution interface diagram

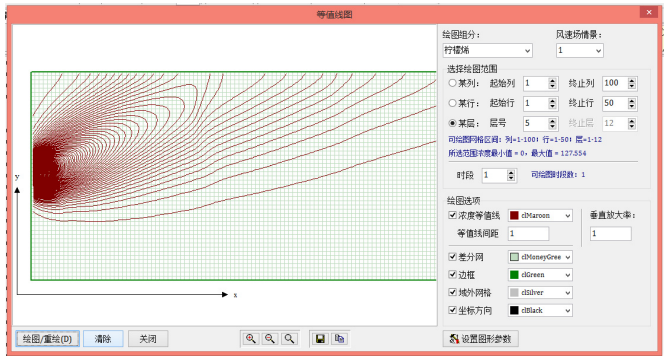

(a) Isogram Chart

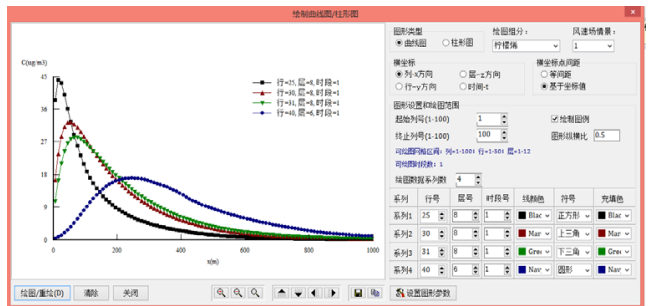

(b) Curve/Column Chart

Fig. 3. The results of the calculation map the interface

\subsection{Governing Equation}

ModOdor uses convection-diffusion spreads as a calculated governing equation, under the above assumptions, the coordinate origin is located in the lower left rear corner of the study domain, the $x$-axis points to the right, they-axis points forward, the $z$-axis points up (Figure 4), and can establish a mathematical model of the non-steady state flat current diffusion of the foul-smelling gas, the micro equation is as follows: 


$$
\begin{aligned}
\frac{\partial C}{\partial t}= & \frac{\partial}{\partial x}\left(K_{x} \frac{\partial C}{\partial x}\right)+\frac{\partial}{\partial y}\left(K_{y} \frac{\partial C}{\partial y}\right)+\frac{\partial}{\partial z}\left(K_{z} \frac{\partial C}{\partial z}\right)+\frac{\partial}{\partial x}\left(K_{x} \frac{\partial C}{\partial x}-u_{x} C\right) \\
& +\frac{\partial}{\partial y}\left(K_{y} \frac{\partial C}{\partial y}-u_{y} C\right)+\frac{\partial}{\partial z}\left(K_{z} \frac{\partial C}{\partial z}-u_{z} C\right)-\left(W+k+k_{w}\right) C+S \\
& (x, y, z) \in G, t>0
\end{aligned}
$$

Initial conditions:

$$
\left.C(x, y, z, t)\right|_{t=0}=C_{0}(x, y, z), \quad(x, y, z) \in G
$$

The first type of boundary condition

$$
\left.C(x, y, z, t)\right|_{\Gamma_{1}}=C_{1}(x, y, z, t), \quad(x, y, z) \in \Gamma_{1}, \quad t>0
$$

The second type of boundary condition

$$
\begin{gathered}
{\left[K_{x} \frac{\partial C}{\partial x} \cos (n, x)+K_{y} \frac{\partial C}{\partial y} \cos (n, y)+K_{z} \frac{\partial C}{\partial z} \cos (n, z)\right]_{\Gamma_{2}}=f(x, y, z, t)} \\
(x, y, z) \in \Gamma_{2}, t>0
\end{gathered}
$$

The third type of boundary condition

$$
\begin{aligned}
& {\left[K_{x} \frac{\partial C}{\partial x} \cos (n, x)+K_{y} \frac{\partial C}{\partial y} \cos (n, y)+K_{z} \frac{\partial C}{\partial z} \cos (n, z)\right]_{\Gamma_{2}}=f(x, y, z, t)} \\
& (x, y, z) \in \Gamma_{2}, t>0
\end{aligned}
$$

$C(x, y, z, t)$ : concentration of odor gases, $\mu \mathrm{g} \cdot \mathrm{m}^{-3} ; K_{x}$, $K_{y}, K_{z}$ : the principal value of the turbulent diffusion coefficient tensor, $\mathrm{m}^{2} \cdot \mathrm{s}^{-1} ; W$ : gas sink intensity, volume of gas taken away per unit of time sink volume (input positive value $), \mathrm{m}^{3} \cdot\left(\mathrm{m}^{3} \cdot \mathrm{s}\right)^{-1}$, whose concentration is equal to $C(x, y, z \times, \mathrm{t}) ; S$ : source sink term, $\mu \mathrm{g} \cdot \mathrm{m}^{-3} \cdot \mathrm{s}^{-1}$, the mass of odor gases emitted per unit of time unit of source volume; $k$ : first-level chemical reaction constant, $\mathrm{s}^{-1} ; k_{\mathrm{w}}$ : removal factor in wet deposition, $\mathrm{s}^{-1} ; u_{x}, u_{y}, u_{z}$ : coordinates of wind speed, $\mathrm{m} \cdot \mathrm{s}^{-1} ; C_{0}(\mathrm{x}, y, z)$ : The given concentration on the first type of boundary condition $\Gamma_{1}$, $\mu \mathrm{g} \cdot \mathrm{m}^{-3} ; f(\mathrm{x}, y, z, t)$ : A given turbulence diffusion pass on the second type of boundary $\Gamma_{2}, \mu \mathrm{g} \cdot \mathrm{m}^{-2} \cdot \mathrm{s}^{-1}$, for the odor gas mass that enters the study domain vertically through the unit boundary area per unit of time due to turbulence diffusion; $g(\mathrm{x}, \mathrm{y}, \mathrm{z}, \mathrm{t})$ :The amount of flat and turbulent diffusion diffusion given on the third type of boundary $\Gamma_{3}, \mu \mathrm{g} \cdot \mathrm{m}^{-2} \cdot \mathrm{s}^{-1}$, the odor gas mass perpendicular to the study domain perpendicularly through the unit boundary area under the joint action of wind speed and turbulence diffusion; $\cos (n, x), \cos (n, y), \cos (n, z)$ : direction cosine; $G$ : Spatial research domain; $\Gamma$ : Boundaries of the study domain, $\Gamma_{1}+\Gamma_{2}+\Gamma_{3}=\Gamma ; x, y, z$ : the position of the calculated point, $\mathrm{m}$; $t$ : calculated time, $\mathrm{s}$.

\subsection{The division of the time domain and the spatial domain}

ModOdor allows you to set "in-domain mesh" and "out-of-domain mesh" in differential meshes, a feature that allows ModOdor to finely simulate complex changes in terrain and ground buildings, making our models widely applicable. The term " out-of-domain mesh " refers to which grids in the differential grid are outside the boundaries of the study domain. Out-of-domain mesh do not participate in simulation calculations because they are outside the study domain. All grids except the out-of-domain grid are in-domain grids. An in-domain grid is a grid that implements simulated calculations. Fig. 4. shows ModOdor's situation in which complex terrain conditions are depicted by setting an out-of-domain mesh.

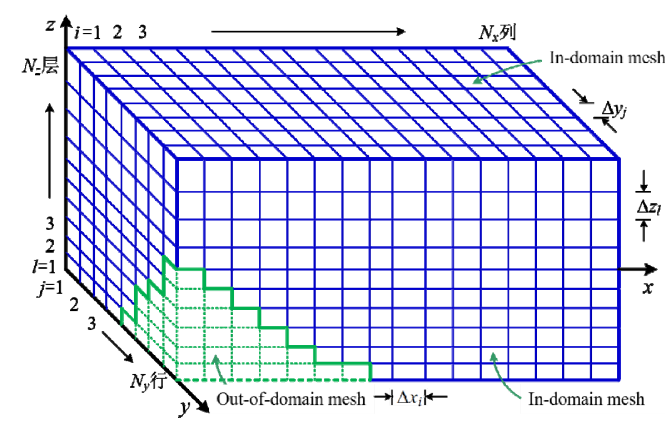

Fig. 4. Three-dimensional spatially limited differential section mesh

If the simulation area has terrain fluctuations, the height of the lowest point in the simulation area is calculated to be $z_{0}$, and the study domain issectioned to form a differential mesh. Based on the intersection of differential mesh and terrain, the mesh is determined to be in-domain or out-of-domain mesh: the mesh below the surface of the earth is an out-of-domain mesh, and the reverse is an in-domain mesh. In this way, the ups and downs of the surface (including buildings) are approximated by the changes in the folds of the differential mesh. The finer the differential mesh, the higher the accuracy of this approximation. (Fig.5.)

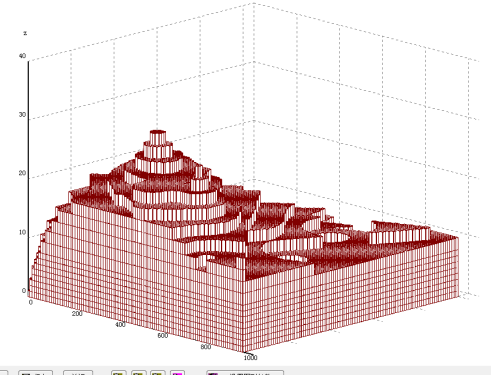

(a)Out-of-domain mesh simulates terrain changes

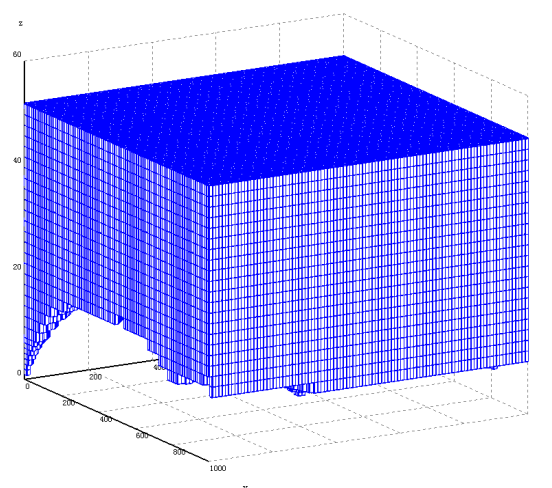

(b)In-domain compute grid

Fig. 5. ModOdor sets up an Out-of-domain mesh to simulate a complex topographic interface map 


\section{Simulation of the diffusion of odorous gases in livestock and poultry farms}

\subsection{Basic information on livestock and poultry farms}

In this study, three different types of intensive farms (RM Ranch, GDK Pig Farm, LDK Chicken Farm) of medium size in Z County, Province B, were selected as the research objects. The scale and basic conditions of farming are in table 3 .

Table 3. Basic information table for farms

\begin{tabular}{lllll}
\hline Name of the farm & Breeding species & Location & $\begin{array}{l}\text { The amount of columns } \\
\text { stored } \\
\text { (Head /Feather) }\end{array}$ & Heap time \\
\hline RM Ranch & Cow & Changshan Town & 500 & $4-5$ \\
GDK Pig Farm & Pig & The town of Jiaoqiao & 530 & 7 \\
LDK Chicken Farm & Layer & The town of Jiaoqiao & 40000 & 7 \\
\hline
\end{tabular}

\subsection{Weather conditions}

The farm selected in the simulation case is located in B City Z County, S Province, is a warm temperate humid continental monsoon climate zone, the annual average temperature of $13.1{ }^{\circ} \mathrm{C}$, relative humidity of $64 \%$, the dominant wind direction is west wind (wind frequency 9.76 percent), static wind frequency is $9.69 \%$, the average annual wind speed is $2.6 \mathrm{~m} / \mathrm{s}$.

\subsection{The ModOdor model simulates input conditions}

The concentration distribution of the main odor pollutants $\left(\mathrm{NH}_{3}\right)$ in the downwind of three farms was simulated using the ModOdor model, and the input conditions of the model were as follows:

-----Page 1: Differential grid and time period

Spatial domain profiling forms a finite differential mesh

Number of columns (x)80, study domain length (m): $800, \mathrm{~d}_{x}=10 \mathrm{~m}$

Number of rows (y)80, study field width(m): 800 , $\mathrm{d}_{y}=10 \mathrm{~m}$

Number of layers)20, study domain height(m): 159, $\mathrm{d}_{z}=1 \mathrm{~m}$ (Tier 1-4), $5 \mathrm{~m}$ (Tier 5), $10 \mathrm{~m}$ (Tier 6-20)

The stable state of the simulation problem: steady state

Simulation group score: 2

-----Page 2: Grid nature-----

The entire domain is a calculated grid, not taking into account the ups and downs of the terrain

------Page 3: Wind speed field $(u x, u y, u z)$------

Wind speed field selection: same wind speed across the domain, $u x=3 \mathrm{~m} / \mathrm{s}, u y=3 \mathrm{~m} / \mathrm{s}, u z=3 \mathrm{~m} / \mathrm{s}$, $\mathrm{Ky}, \mathrm{Kz})------$

----Page 4: Turbulence diffusion coefficient $(\mathrm{Kx}$,

Diffusion coefficient selection: The domain-wide diffusion coefficient is the same

$K x=100.0 \mathrm{~m}^{2} / \mathrm{s}, \quad K y=100.0 \mathrm{~m}^{2} / \mathrm{s}, \quad K z=27.97 \mathrm{~m}^{2} / \mathrm{s}$

------Page 5: Wet and dry subsidence parameters

Ignore dry and wet sending

------Page 8: Boundary conditions------

The default settings for studying domain boundaries are as follows:
Front border: open; rear border: open; left border: open;

Right boundary: open; upper boundary: open; lower boundary: closed.

------Page 9: Source and set concentration conditions------

Face source settings

Cow:

$X y$ plane, area $1500 \mathrm{~m}^{2}(30 \times 50 \mathrm{~m})$, source height $3 \mathrm{~m}, \mathrm{NH}_{3}=69.230 \mu \mathrm{g} / \mathrm{m}^{2} \cdot \mathrm{s}$

Cow dung heap:

Xy plane, area $200 \mathrm{~m}^{2}(10 \times 20 \mathrm{~m})$, source height $1.5 \mathrm{~m}, \mathrm{NH}_{3}=495.450 \mu \mathrm{g} / \mathrm{m}^{2} \cdot \mathrm{s}$;

Pig House:

$X y$ plane, area $1500 \mathrm{~m}^{2}(30 \times 50 \mathrm{~m})$, source height 3 $\mathrm{m}, \mathrm{NH}_{3}=54.900 \mu \mathrm{g} / \mathrm{m}^{2} \cdot \mathrm{s}$

Pig manure heap:

$X y$ plane, area $200 \mathrm{~m}^{2}(10 \times 20 \mathrm{~m})$, source height 1.5 $\mathrm{m}, \mathrm{NH}_{3}=50.400 \mu \mathrm{g} / \mathrm{m}^{2} \cdot \mathrm{s}$;

Layer hens coops:

$X y$ plane, area $2400 \mathrm{~m}^{2}(40 \times 60 \mathrm{~m})$, source height 3 $\mathrm{m}, \mathrm{NH}_{3}=255.79 \mu \mathrm{g} / \mathrm{m}^{2} \cdot \mathrm{s}$;

Layer hens manure heap:

$X y$ plane, area $600 \mathrm{~m}^{2}(20 \times 30 \mathrm{~m})$, source height $1.5 \mathrm{~m}, \mathrm{NH}_{3}=190.25 \mu \mathrm{g} / \mathrm{m}^{2} \cdot \mathrm{s}$

------Page 10: Chemical reaction parameters------

Chemical reaction options: Ignore chemical reactions

------Page 11:Iterative solution parameters------

Maximum iterations: 100,000, convergence absolute error:1E-5, relaxation factor: 1.2 , timestep reduction factor: 0.05

\subsection{The result of the calculation}

The diffusion simulation of the release of $\mathrm{NH}_{3}$ from livestock and poultry farms was performed using ModOdor to analyze the distribution of foul odor pollution concentrations in the floor layer $(1.5 \mathrm{~m}$ high), as shown in Fig. 6.-Fig. 8. 


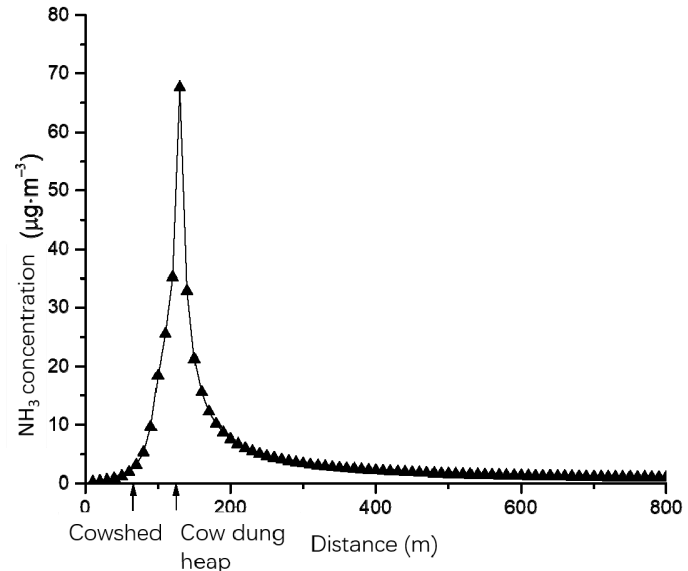

Fig. 6. Distribution of the concentration of ammonia in the wind under the Inma Ranch

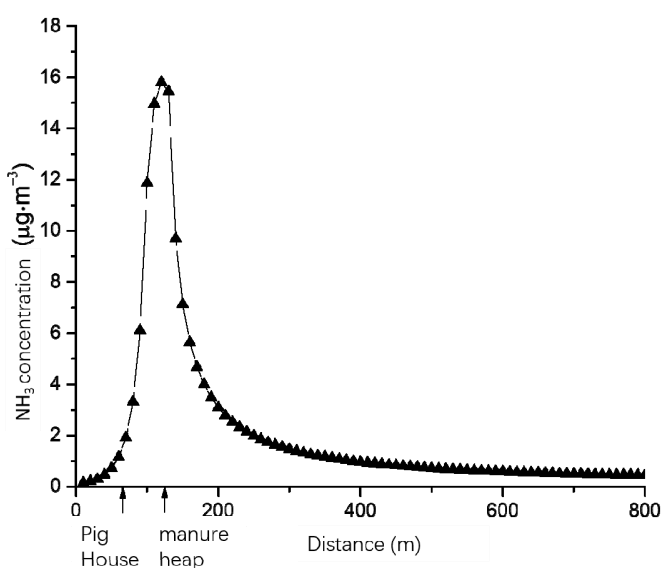

Fig. 7. Distribution of the concentration of ammonia in the wind under the pig farm at the mouth of the high road

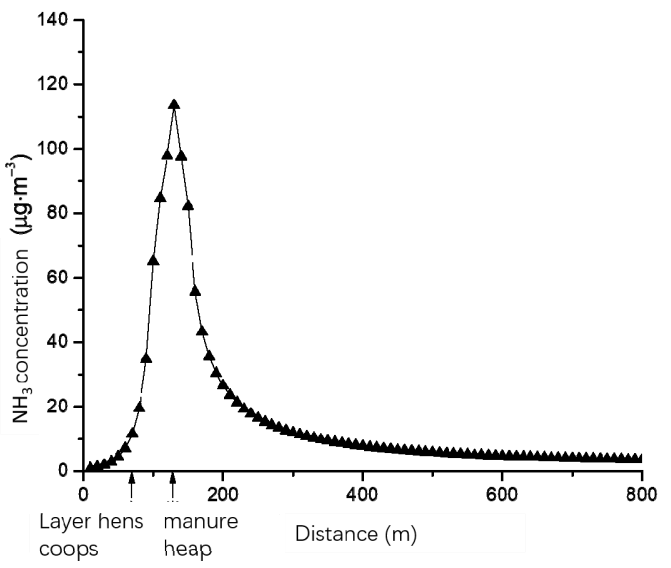

Fig. 8. Distribution of the concentration of ammonia in the wind under Liu Daokou layer hens farm

\subsection{Results}

The results of software simulation show that the odorous pollutants of livestock and poultry farms are mainly produced in the "house-fecal storage" link. In the farm, when the feces moisture is too much or no fresh air, it will form a local oxygen-free environment in the feces.
Thereby producing and releasing odor gas. Similarly, sewage discharged from farms produces odorous gases when oxygen is scarce.

Compared with the three main breeding categories, dairy farms are in a semi-open environment, the resolution storage time is relatively short, the peak of odorous gas is steep, which means that ammonia diffusion is faster, that is, the impact on the surrounding environment is eliminated faster. While pig breeding and egg and chicken breeding for feeding, feces storage time is relatively long, the peak obvious width is large, the impact on the surrounding environment is larger, diffusion intensity convergence is slower.

\section{Discussion}

\subsection{Classification management by breeding scale}

From the simulation results and foreign experience, developed countries and regions are mostly concerned about the scale of animal husbandry pollution control. The United States would take farms of a certain scale as point source management, to achieve continuous discharge under emission standards. Non-point source pollution management is according to the national breeding industry non-point source pollution prevention and control plan to establish all levels of government's non-point source pollution management plan, and to improve the non-point source pollution monitoring, census \& evaluation system and implementation of the integrated watershed management plan. Combined with the characteristics of small-scale farming in China, the idea of classification management in developed countries, as well as the policy and practical experience in pollution control of non-point sources (e.g. BMPs and TMDL programs in the United States) have some reference significance.

\subsection{Reasonable regional breeding planning}

Developed countries generally attach importance to the way of combination of farming and animal husbandry. Considering the development trend of animal husbandry and the characteristics of China's meat industry, we can learn from the "balanced regional integration of breeding" livestock and poultry farming methods which first implemented by EU countries, which is to combine with regional vegetation resources, farmland area, soil fertility, human resources and other conditions of comprehensive planning of the area's livestock capacity. In large and medium-sized intensive livestock and poultry farms, we could promote the establishment of the application of organic fertilizer green crop planting base, and the implementation of relevant preferential policies, so that the application of organic fertilizer green products to obtain rich market returns. 


\subsection{Encourage the resource utilization of livestock and poultry faeces}

From the simulation results, the storage and disposal facilities of farmed environmental feces are the main sources of odor emissions. How to properly treat with the farm manure is an important aspect of controlling the environmental pollution of animal husbandry. Providing high-quality and efficient organic fertilizer sources to agricultural production is a common approach in developed countries. The animal and poultry manure in intensive breeding industry is treated harmlessly and made into multi-potable organic bio-fertilizer for agricultural production. Minnesota farms, for example, use livestock and poultry waste and garbage to generate electricity, not only to deal with garbage, but also to provide residents with new energy. The pollution load of wastewater in animal husbandry is very high, and the cost of direct biological treatment is high. It is encouraged that biogasification, acidification and precipitation and at the end using biological ponds and land treatment systems.

\subsection{Strengthen environmental monitoring of animal and poultry pollution}

The current development of livestock and poultry breeding industry in China has caused serious pollution to surface water and groundwater in some areas, and environmental monitoring of pollution in livestock and poultry farming industry should be strengthened. Investigation of the current situation of animal and poultry pollution with the stakeholder feedback should be carried out. Ecological protection information should also be provided for the prevention and control of livestock and poultry pollution as the basis for the establishment of scientific management procedures.

\section{Conclusion}

Software "ModOdor" could simulate the spread of odor pollutants well under different breeding conditions based on environmental monitoring data of the Internet of Things system. According to the simulation result, the characteristics of pollutant diffusion in typical farms could provide decision reference to odor hygienic buffer zone and minimum shelter distance. This study provides an effective exploration for achieving the ecological and safety objectives of livestock farming.

\section{Acknowledgements}

This research was funded by the National Key Research and Development Program of China (2017YFD0502006) and the Central Public-interest Scientific Institution Basal Research Fund of China (JBYW-AII-2020-20).

\section{References}

1. LO Y C M, KOZIEL J A,CAI L S, et al. Journal of Environmental Quality, 37(2), 521-534 (2008)

2. SCHIFFMAN S S, BENNETT J L, RAYMER J H. Agricultural and Forest Meteorology, 108(3), 213-240 (2001)

3. BLUNDEN J, ANEJA V P, LONNEMAN W A. Atmospheric Environment, 39(36), 6707-6718 (2005)

4. CIGANEK M, NECA J. Veterinarni Medicina, 53(12), 641-651 (2008)

5. SCHAEFFER J. Sampling. Agriculture and Environment, 3(2/3), 121-127 (1977)

6. KIM K Y, JONG KO H, TAE KIM H, et al. Journal of Environmental Management, 88(2), 195-202 (2008)

7. RAPPERT S, M LLER R. Waste Management, 25(9), 887-907 (2005)

8. FEILBERG A, LIU D Z, ADAMSEN A P S, et al. Environmental Science \& Technology, 44, 5894-5900 (2010)

9. ZHU J. Agriculture, Ecosystems \& Environment, 78(2), 93-106 (2000)

10. ZAHN J A, HATFIELD J L, DO Y S, et al. Journal of Environmental Quality, 26(6), 1687-1696 (1997)

11. HOBBS P J, MISSELBROOK $\mathrm{T}$ H, PAIN B F. Journal of the Science of Food and Agriculture, 73(4), 437-445 (1997)

12. YAO H Q, CHOI H L, ZHU K, et al. Atmospheric Environment, 45(15), 2577-2584 (2011)

13. ZHANG R, YAMAMOTO T, BUNDY D S. IEEE Transactions on Industry Applications, 32(1),113-117 (1996)

14. ZHENG Fang. Beijing: Chinese Academy of Agricultural Sciences (2010)

15. HAYES $E$ T, CURRAN $T$, DODD $V$ A. Bioresource Technology,97,933-939 (2006)

16. PARKER D B, GILLEY J, WOODBURY B, et al. Atmospheric Environment, 66: 91-1000 (2013)

17. O'NEILL D H, PHILLIPS V R. Journal of Agricultural Engineering Research, 53: 23-50 (1992)

18. LIU Z F, POWERS W, MUKHTAR S. Applied Engineering in Agriculture, 30(3): 477-492 (2014)

19. M RTENSSON L, MAGNUSSON M, SHEN Y, et al. Agriculture, Ecosystems \& Environment, 75(1/2), 101-108 (1999)

20. LIM T T, HEBER A, NI J Q, et al. Transactions of the ASAE, 47(6), 2041-2050 (2002) 